\title{
Strategic Decisions in the Crisis Stages of the Organization
}

\author{
Prof. Dr. Tzveta Zafirova \\ University of Economics - Varna, Varna, Bulgaria \\ tzveta_zafirova@ue-varna.bg
}

\begin{abstract}
The paper describes the main theoretical essence and stages of development of organizational crises. Based on the concept of strategic crisis management and practice in its application are outlined and systematized strategic alternatives for organizations depending on the stage of the crisis in which they are located.
\end{abstract}

Keywords: strategic alternatives, life cycle of crisis, stage of crisis, strategic crisis management, crisis strategy

JEL Code: M16, M19 DOI: https://doi.org/10.36997/IJUSV-ESS/2020.9.1.100

\section{Въведение}

Много изследователи определят кризите като неизбежно явление, което съпътства социалните системи. Те са неразделна част от функционирането и развитието на съвременните организации. Кризите могат да възникнат и в зависимост от случая могат да бъдат опустошителни за организацията, но те могат да бъдат и управлявани. В този процес значително място заема методологията на стратегическото управление.

Dubrovski (2007) посочва, че „някои от характеристиките на критичните обстоятелства, в които мениджмънтът може да се окаже, показват, че особеностите на процеса на управление на организацията в криза се различава от „класическото” стратегическо управление".

Това означава, че се изисква нов начин на мислене за стратегията в условията на неопределеност, несигурност и риск, когато кризите са често явление. По този начин се доказва и потребността от съчетаване на подходите в двата процеса - управление на кризите и стратегическо управление. Интегрирането им ще позволи да се намали неопределеността на решенията за бъдещето. Само правилният избор на подходяща стратегия може да помогне на организацията за предотвратяването на кризите или позитивния изход от тях.

Целта на настоящата публикация е да посочи какви трябва да бъдат стратегическите алтернативи на организациите в зависимост от етапа на кризата, в която се намират.

Изследването се основава на голям брой проучени литературни източници, показващи в теоретичен и практически аспект стратегически решения в различни организации по време на етапите на организационната криза. Възприета е тезата, че управлението на кризи е неразривно свързано със стратегическото управление и двата процеса трябва да бъдат интегрирани в един процес на стратегическо кризисно управление.

\section{1. Сыщност на организационните кризи}

Много учени се обединяват около становището, че кризите са неизбежни за организациите. Spillan (2003) посочва, че „рано или късно, всяка организация ще бъде изправена пред криза в някакъв вид.”. A Wilson (2004) стига до заключението, че те не са дискриминационни - всъщност не избират „дали”, а „кога”.

Макар че не всички кризи могат да бъдат предвидени, а и едва ли предотвратени, „всяка от тях може да се управлява много по-ефективно, ако ги разбираме и да практикуваме най-доброто от това, което е в човешките възможности" (Mitroff, 2001). От гледна точка на параметрите трябва задължително да посочим становището на Mitroff (2001), че „обект на кризисния мениджмънт са основно кризите, причинени от човека". 
Дефинирането на процеса на управление на кризи преминава през различни трансформации в своята еволюция. То е започнало твърде късно в сравнение с кризите на макрониво. Съществуващите изследвания на механизма на управление на кризи в организациите могат да бъдат класифицирани в две направления. Първото е фокусирано върху това как да се даде благоприятен отговор на кризата, когато тя вече се е случила и не се отделя никакво внимание на това, което една организация трябва да направи преди и след нея. Във второто направление на научните изследвания, управлението на организационната криза е разделено на няколко фази, като процедурите и подходите във всяка са изброени подробно. В тях, кризисното управление се счита за обединяващ механизъм.

Всеобщото мнение на учените в областта е, че дискусията за кризисния мениджмънт в научната литература започва с кризата с медикамента Тайленол на Johnson\&Johnson през 1982 г. Компанията се справя изключително добре в тази кризисна ситуация и това и до днес се счита за модел или стандарт за кризисен мениджмънт (Mitroff, 2001).

След излизането на първата сериозна монография по управление на кризи на Steven Fink (Steven Fink: Crisis Management: Planning for the Inevitable. NY: Blackprint, 1986) ca написани доста научни публикации в областта. Всички те са посветени на управленските проблеми в кризисни ситуации, като са описани функциите на управление в тях.

Проблемите на кризисния мениджмънт са анализирани от много учени като поизвестни са: Fink (1986), Shrivastava, Mitroff, Miller \& Miglani (1988), Mayer (1992), Preble (1993), Darling et al. (1996), Darling \& Cesh (1998), Pearson \& Clair (1998), Boin \& Lagadec (2000), Fink (2002), Mitroff et al. (2001, 2006), Ulmer et al. (2007) и др.

Управлението на кризи (Crisis Management) се дефинира от Shrivastava, Mitroff, Miller \& Miglani (1988) като „процес c холистичен подход, който идентифицира потенциилните въздействия, които застрашават организаџията. Те осигуряват рамка за изграждането на устойчивост, с възможност за ефективен отговор, който да зашитава интересите на нейните стейкхолдери, репутацията, търговската марка и иенностите, както и ефективно възстановяване на оперативните способности". Това е едно доста изчерпателно и всеобхватно тълкуване на целия процес на управлението на кризите, включващ както тяхната същност, така и съдържанието им. То се възприема от много западни учени. По същество, управлението на кризи представлява процес, чрез който една организация се занимава с голямо събитие, което заплашва да навреди на нея, на стейкхолдерите й или на широката общественост.

Preble (1997) комбинира няколко дефиниции, първата от които е „организационнобазирано бедствие, което причинява големи щети и социални разстройства, включвайки множество заинтересовани страни (стейкхолдери), и разгръщайки се чрез комплекс от технологични, организационни и социални процеси (Shrivastava et al., 1988)".

Паралелно с тия дефиниции се появяват и такива, които се опитват да обяснят процеса на кризисния мениджмънт от гледна точка на теорията за хаоса. Признаването на нелинейно взаимодействие между компонентите в процеса на управление карат Murphy (1996) и по-късно Seeger (2002) да приложат тази теория. Но този подход не е спечелил много привърженици. Всъщност Seeger (2002) признава, че при кризи изследователите и практиците са фокусирани преди всичко върху краткосрочни цели за разрешаването им възможно най-бързо с по-малко последици, за разлика от дългосрочните времеви рамки и поширокия мащаб, необходими за теорията на хаоса. Този подход, според нас, е погрешен, тъй като са необходими стратегически решения за изход от кризата.

Американският учен Coombs (2007) има съвсем различно становище за дефинирането на процеса на управление на кризи на основата на много изследвани кризисни ситуации и литературни източници. Неговото обяснение за кризисния мениджмънт еволюира от подготовката за извънредни ситуации до управление на тази база, като се състои от набор от четири взаимосвързани етапи: превенция, подготовка, реакция и ревизия (Coombs, 2007). 
Нашето законодателство сьщо е наложило своето дефиниране на процеса на управление на кризи в Закона за управление на кризите от 2005 г., чл.3, ал.1 - „комплекс от дейности на компетентни органи, насочени към предотвратяване възникването и развитието на кризи и тяхното овладяване".

Освен посочените, съществуват и други тълкувания на понятието „управление на кризи", които по същество не се различават от тях. Те не могат да бъдат обхванати в еднозначно дефиниране на процеса и поради тази причина ще предложим по-опростено, но изчерпателно в значителна степен тълкуване - „Управлението на кризи е процес, при който една организачия мобилизира своите усилия в разрешаването на сериозен проблем, който застрашава да навреди на нея, на нейните стейкхолдери, или на широката общественост".

\section{2. Тристыпков модел на управление на кризи}

В специализираната литература са известни много изследвания за жизнения цикъл на кризите, както и модели за управление на организационни кризи. В теорията и практиката е особено популярен един тристъпков модел, като не е ясно определим неговият създател. Той се препоръчва от различни експерти по управление на кризи - Mitchel (1986); Barch (1994); Guth (1995); Seeger, Sellnow \& Ulmer (2003). „Тристепенният модел не е свързан с някакви специфични теории, но вероятно е произлязъл от няколко изследователски усилия като цялостна аналитична структура" (Seeger, Sellnow \& Ulmer, 2003).

Coombs (2007) описва този модел, създаден съгласно трите етапа на жизнения цикъл на кризата на основата на управлението на дейностите:

\section{precrisis (преди кризисен) - crisis (кризисен) - postcrisis (следкризисен)}

Coombs (2007) не случайно ги описва като макро етапи. Понятието макро, което той използва, определя етапите като обобщени и че всеки съдържа някакъв набор от подетапи на микро ниво. Тази теза се доказва и с моделите на Fink (1986) и Mitroff (1994).

Тази класификация според етапите на жизнения цикъл на кризите е основата на много изследвания и модели в областта на управлението им. Тя е резултат на много творчески търсения на изследователите в областта. Нашето становище е, че третият етап трябва да остане с наименованието „следкризисен”, но трябва да се промени съдържанието му. Задължително трябва да има включени две алтернативи - при позитивен и за негативен изход от кризата, когато е невъзможно предприятието да излезе от нея без външна намеса след кризата на ликвидността.

\section{3. Стратегическо управление на организационни кризи}

В специализираната литература за първи пьт в 1987 г. Shrivastava \& Mitroff започват да защитават тезата, че в управлението на кризата трябва да бъде приложен стратегическият подход за управление. Това се потвърждава и от изложените модели за управление на кризите, предложени от някои учени - на Burnett (1998), основан на етапите в процеса на стратегическо управление и на Jaques (2007) - етап избор на стратегия и др.

Preble (1997) доказва как интегрирането на управлението на кризи и процеса на стратегическо управление могат да предоставят на организациите отбранителна възможност за предотвратяване на развитието на кризите или намаляване на тяхното въздействие, ако те са възникнали.

Smith (1992) доразвива теорията в областта като твърди, че е налице връзка, която свързва необратимо процеса на управление на кризи и процеса на стратегическо управление. Действителната поява на организационна криза може да доведе до промени в съществуващите стратегии и стратегически действия, както посочват Starbuck \& Milliken (1988). Нашето становище е, че дори промяната на стратегиите не нарушава логиката 
на процеса на стратегическо управление. Обратно, липсата на стратегически действия под формата на кризисни сценарии, може да доведе до негативни резултати. Освен това, известните американски учени Shrivastava $\&$ Mitroff (1987) твърдят в резултат на значителен брой изследвания, че многобройните кризи се случват, защото са налице по-ранни неуспехи в процеса на стратегическо управление на организацията.

Sheaffer \& Mano-Negrin (2003) подчертават значението на стратегическата ориентация в управлението на кризи, тьй като „подкрепата на стратегията ... е от ключово значение за оценката на степента, в която дадена организация е позиционирана за ефективно справяне с отрицателните последици от промяната в условията на средата".

Въпреки това, точното естество на тези връзки тепърва се уточнява, интегрирането в преобладаващия стратегически модел за управление на процеса все още не е изследвано задълбочено и учените и практиците в областта на стратегическото управление като цяло досега не са анализирали детайлно тази връзка.

Дългосрочната ориентация на стратегическите кризисни решения ще игнорира потенциалните проблеми, които могат сериозно да накърнят ползите от процеса на кризисното управление. Бихме могли да дадем много съвременни примери в тази насока както световни, така и български, които съпътстват нашето ежедневие и запълват медийното пространство.

Стратегическото управление самостоятелно не обрыща достатъчно внимание на защитата на организацията при появата на кризисни явления. Процесьт на управлението на кризи може да подобри ориентацията на стратегическото управление. Както посочихме, стратегическото управление включва формулирането, изпълнението и оценката на стратегии, насочени към постигане на целите на организацията. А управлението на кризи се занимава с опит да се идентифицират и прогнозират областите на потенциални кризи, развитието на дейностите и мерките, насочени към предотвратяването на кризи, както и свеждане до минимум на ефектите или смущенията от кризата, която не може да бъде предотвратена (Wilson, 1992).

В обобщение може да се направи извода, че докато стратегическото управление акцентира на определени фактори на средата (конкуренти, потребители, стейкхолдери и др., създаване и запазване на конкурентни предимства, устойчивост в развитието и финансов успех), управлението на кризи включва и безопасност и надеждност на системите, и други фактори на средата като: терористи, психопати, криминален контингент и т.н. Или стратегическото управление има само съзидателен характер, докато при управлението на кризи се включва и разрушителния аспект.

Както Preble (1997) доказва в своето изследване, управлението на кризи, въпреки че е различна област с други цели, може да бъде допълнение към стратегическото управление. Това се потвърждава и от техните прилики (Mitroff, Pearson \& Pauchant, 1992):

- фокусиране върху отношенията със средата;

- сложна система от заинтересовани страни;

- участието на висшето рьководство;

- грижа за цялата организация;

- израз на един последователен модел;

- представяне на спешни процеси.

Към тях бихме добавили, че част от управленските кризисни решения имат дългосрочен характер и са от изключителна важност за организацията, което ги прави стратегически.

Спецификата на стратегическия подход в управлението в условията на криза е в това, че организацията трябва да се подготви за промените. За да не се превърне това критично време в проблем, е необходимо да има периодичен стратегически анализ, който да диагностицира навреме симптомите на кризата. 
На основа на посочените тези е разработена и концепцията за стратегическото кризисно управление. Тя се прилага с успех в много организации и се развива успешно в последните години, като в някои водещи световни университети има обособени модули за обучение на висши кадри в тази област. Тук възниква необходимостта от дефиниране на понятието „стратегическо управление на кризи”, което ще се различава съществено от класическото определение на „стратегическо управление”. Като се има предвид теоретичните постановки на водещите учени в областите стратегическо управление и управление на кризи, бихме могли да изведем следното собствено тълкуване като пресечна точка и обединяващо двете основни понятия: Стратегическото управление на кризи $e$ процесът на управление, при който се прилага стратегически подход в предотвратяването или справянето с кризисни ситуации, като това е съобразено с промените в средата, с външните възможности и заплахи, както и с потенциала за излизане от кризата или смекчаване на въздействието й.

\section{4. Стратегически алтернативи в зависимост от етапа на кризата}

На основата на задълбочен анализ на литературата в областта можем да направим извода, че няма изведена цялостна типологизация на стратегическите алтернативи пред организацията в условията на криза, обхващаща всички нейни аспекти и проявления.

Изхождайки от определението на М. Porter за стратегия (Porter, 1996), за конкретните условия на кризи бихме формулирали понятието „кризисна стратегия” по следния начин: това е курсът на действие, който организацията незабавно избира, преследвайки целите си в зависимост от фазата на кризата, в която се намира, и съобразявайки се както с възможностите и заплахите от външната среда, така и със собствения си потенциал.

Нашето становище, че най-подходящата класификация за кризисните стратегии е на основата на етапите на кризата, описани от Coombs (2007) - предкризисен, кризисен $u$ следкризисен. В зависимост от етапа, в който се намира организацията, можем да разделим стратегическите алтернативи на:

(1) кризисни стратегии, които е необходимо да бъдат избрани преди кризата, за да предотвратят нейното настъпване т.е. превенцията;

(2) кризисни стратегии, когато кризата е настьпила, т.е. справянето с нея или т.нар. оцеляване;

(3) кризисни стратегии, когато кризата е свършила и организацията се е справила успешно, т.е. възстановяване (оздравяването);

(4) кризисни стратегии, при което резултатьт от кризата е неуспешен за организацията.

При всеки един от тях се следва в някаква степен методологията на стратегическото управление, отчитайки особеностите на фазата на кризата (фиг.1). На практика от нея и от формата на кризата зависи и стратегическият избор. Нашето класифициране на типовете стратегии според един или друг етап се основава на теорията на стратегическото управление, практическия опит и изследване на голям брой казуси в областта.

Първият процес е свързан с проблема за прогнозируемостта и предсказването на бъдещето. Очевидно е, че времето и мащаба на бъдещите кризисни явления не могат да бъдат предсказани. Както е известно, теоретиците по стратегическо управление не дават еднозначен отговор на този въпрос. В класическите разработки по този проблем Mintzberg (Mintzberg, 1990) и Ansoff (Ansoff, 1991) обосновават противоположни становища и препоръки по този процес, свързан със избора на стратегия за предотвратяване на кризата.

Към стратегиите за предотвратяването на кризите можем да включим: обръщане, жътва, преструктуриране на организацията и на портфейла, на международния портфейл, „Син океан”, аутсорсинг, офшоринг, офшорен аутсорсинг, кльстер (напр. Dimitrova (2020), придобиване, погльщане, на интернационализация и др. 
При втория процес стратегията зависи не само от степента на кризата, нейния мащаб и действие, но и от потенциала на организацията да се справи с нея. Това означава мобилизация на интелектуалните ресурси за бързо вземане на стратегически решения за смекчаване действията на кризата и оцеляване на организацията. Формира се т.нар. стратегическа реакция на кризата. Тя трябва да доведе до оцеляване на организацията. Тук имаме два варианта - излизане от кризата или невъзможност това да се случи. Действията зависят от това в какъв аспект ще се развие кризисната ситуация.

Към стратегиите за оцеляване бихме могли да причислим съкращаване, лишаване от права (продажба на активи), сливане, стратегическите алианси, пленничество и т.н.

Третият процес е свързан с оздравяването на организацията, в случай, че е оцеляла след кризисната ситуация. Стратегическият избор в следкризисното състояние се състои в ликвидиране на последствията от кризата с цел организацията да се възвърне към нейната жизнеспособност, като се стреми да достигне поне нивото на показателите си от предкризисния етап.

Ако организацията успее да преодолее кризата, е необходимо в следкризисния етап да избере т.нар. стратегия за възстановяване или обръщане. Като се има предвид, че в следкризисния етап организацията няма да разполага с достатъчно средства за възстановяването си и започване на оздравителни процеси, е необходимо да се изберат такива стратегии, които не изискват големи инвестиции, а имат бърз положителен резултат. Такива са стратегиите пазарно развитие, продуктово развитие, проникване, консолидация, реинженеринг на бизнес процесите и др.

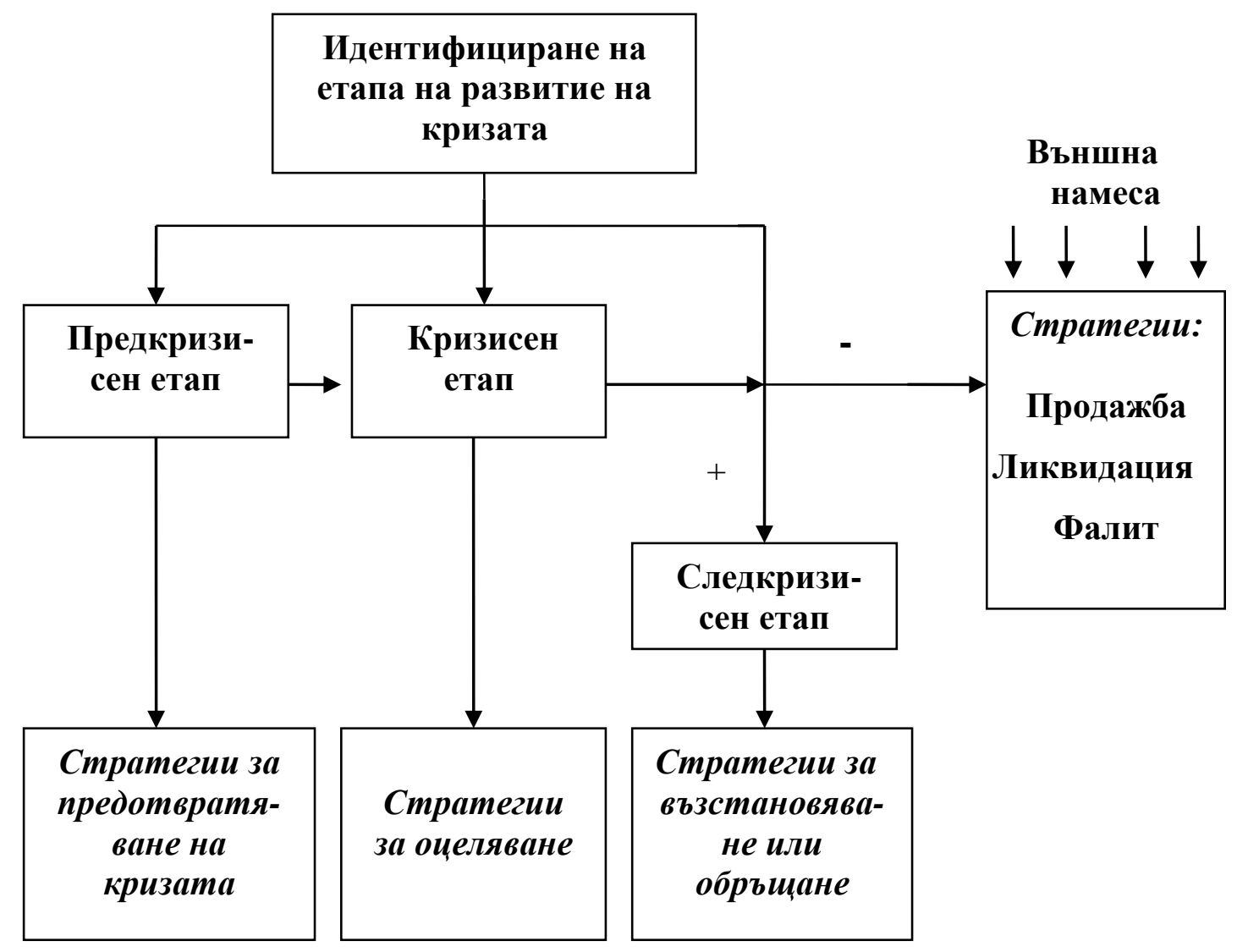

Фигура 1. Кризисни стратегии в зависимост от етапа на кризата

При четвъртия процес няма много алтернативи. В някои случаи промените във външната среда или вътрешните изменения могат да доведат до това, че по-рано 
привлекателна сфера на дейността престава да носи необходимата печалба и единствено правилното решение е прекратяването на дейността в рамките на портфейла. Тук възникват няколко възможности: първата - да се продаде организацията (продажба), която повече не е привлекателна или т.нар. „дивестиция”. Bтората е да се ликвидира бизнеса (дейността), а третата - да се изчака обявяване в несъстоятелност (банкрут).

Този процес е свързан с кризата на ликвидността на организацията, която е толкова дълбока, че не е възможно връщането на жизнеспособността на организацията без външна намеса.

$\mathrm{C}$ посочените стратегии не се изчерпват всички възможни разновидности за условията на криза. В специализираната литература по управление на промените също се предлагат различни подходи и стратегически решения (Kuzmanova, 2019). Посочените от нас са найпопулярните от стратегическото управление, които са регистрирани на този етап на развитие на световната икономика. Бъдещето вероятно ще наложи и други, по-подходящи за глобализиращия се свят стратегии за предотвратяване на кризи.

В условията на пандемия, в които се намираме, възниква необходимостта от правилна преценка на етапа на организационната криза. Намесата на държавата за оцеляването на бизнеса вероятно ще наложи и други типове стратегии, освен познатите класически от специализираната литература, тъй като характерът на кризата и нейните специфични особености са различни от досега известните.

\section{Заключение}

От направените разсъждения, изследването на специализираната литература и практиката в областта могат да се изведат следните изводи и обобщения:

1. Процесът на управление на кризи е неразривно свързан с този на стратегическото управление на организацията. Промяната на стратегиите не нарушава логиката и технологията на процеса на стратегическо управление, тъй като в методологията му са заложени цикличност и адаптация към промените. Изследванията на различни казуси, свързани с кризи показват, че те се случват, защото са налице неуспехи в процеса на стратегическо управление на организацията.

2. В кризисни ситуации главната задача е да се намалят възможните рискове, които очакват организацията. Необходимо е да се оцени потенциалната доходност на операциите и да се даде оценка на възможните заплахи. Необходимо е с най-малки разходи да се постигнат поставените цели.

3. За да се достигне до кризисни ситуации вероятно са допуснати някакви грешки от страна на мениджмънта. Важното е да се извлекат поуките от тях, за да не се допускат отново. В този аспект, една от най-важните задачи пред ръководството на организацията е непрекъсната диагностика на средата и в съответствие с нея бързо актуализиране на стратегията. Ако има предварителна организация как да се реагира при различни промени и проблеми, кризата ще бъде предотвратена или по-лека.

4. Стратегията, която трябва да бъде избрана, зависи от етапа на кризата, в която се намира организацията (предкризисен, кризисен или следкризисен) и преодоляването й. Факт e, че всяка организация преминава последователно през трите етапа, но понякога ръководството й не забелязва случващото се или не иска да реагира в първия, а понякога и във втория етап. В други случаи не е реагирала правилно, избирайки неподходяща стратегия и/или мерки. Това налага отново оценка и идентифициране на етапа за вземане на нови стратегически решения. 
5. Съществуват множество различни специфични ситуации, при които не може да се даде еднозначен отговор коя кризисна стратегия да бъде избрана. Не винаги оптималната стратегия е най-подходяща за определена организация в дадена критична ситуация. Стратегическата алтернатива, която тя трябва да избере, зависи от множество фактори на външната и вътрешната среда, както и от целите, които си поставя.

\section{Литература}

1. Zakon za upravlenie na krizite (2005), D.V.,19, (Izm. - D.V., br.102/2006), chl.3, al.1.

2. Ansoff, I. (1991) Critique of Henry Mintzberg's. The Design School: Reconsidering the Basic Premises of Strategic Management. Strategic Management Journal, 12 (6), pp. 449-461.

3. Burnett, J. J. (1998) A Strategic Approach to Managing Crises. Public Relations Review, 24 (4), pp.475-488.

4. Coombs, W. T. (2007) Ongoing Crisis Communication: Planning, Managing and Responding. (2nd ed.) L. A.: SAGE.

5. Dimitrova, G. (2020) Clusters Perspectives for Competitive Position of the Bulgarian Wine Sector. Balkan Scientific Review, 4, 3(9), pp.94-98.

6. Dubrovski, Dr. (2007) Management Mistakes as Causes of Corporate Crises: Countries in Transition. Managing Global Transitions, 5 (4), pp. 333-354.

7. Jaques, T. (2007) Issue Management and Crisis Management: An Integrated, Non-linear, Relational Construct. Public Relations Review, 33 (2), pp. 147-157.

8. Kuzmanova, M. (2019). Managing Change and Innovation in Contemporary Organizations. Izvestia Journal of the Union of Scientists - Varna. Economic Sciences Series, 8 (1), pp. 183190

9. Mintzberg, H. (1990) The Design School: Reconsidering the Basic Premises of Strategic Management. Strategic Management Journal, 11 (3), pp.171-195.

10. Mitroff, I., Anagnos, G. (2001) Managing Crises before They Happen: What Every Execute and Manager Needs to Know about Crisis Management. N.Y.: AMACOM, American Management Association.

11. Mitroff, I. I. (1994) Crisis Management and Environmentalism: A Natural Fit. California Management Review, 36 (2) pp. 101-113.

12. Mitroff, I. I., Pearson, C., Pauchant, T. C. (1992) Crisis Management and Strategic Management: Similarities, Differences and Challenges. In: Shrivastava, P., (ed.) Advances in Strategic Management. JM Press, 8, pp. 235-60.

13. Murphy, P. (1996) Chaos Theory as a Model for Managing Issues and Crisis. Public Relations Review, 22 (2), pp.95-113.

14. Porter, M. E. (1996) What is Strategy?. Harvard Business Review, November-December, pp. 61-78.

15. Preble, J. F. (1997) Integrating the Crisis Management Perspective with the Strategic Management Process. Journal of Management Studies, 34 (5), pp.769-791.

16. Seeger, M. W. (2002) Chaos and Crisis: Propositions for a General Theory of Crisis Communication. Public Relations Review, 28 (4) pp. 329-337.

17. Seeger, M.W., Sellnow, T.L., Ulmer, R.R. (2003) Communication and Organizational Crisis. Westport, CT: Praeger Publishers.

18. Sheaffer, Z., Mano-Negrin, R. (2003) 'Executives' Orientations as Indicators of Crisis Management Policies and Practices. Journal of Management Studies, 40 (2), pp. 573-606. 
19. Shrivastava, P., Mitroff, I. I. (1987) Strategic Management of Corporate Crises. Columbia Journal of World Business, Spring, pp.5-11.

20. Shrivastava, P. Mitroff, I.I., Miller, D., Miglani, A. (1988) Understanding industrial crises. Journal of Management Studies, 25 (4), pp. 285-304.

21. Smith, D. (1992) Commentary: on Crisis Management and Strategic Management. In Shrivastava, P. (ed.), Advances in Strategic Management. JMPress, 8, pp.261-269.

22. Spillan, J. E. (2003) An Explanatory Model for Evaluating Crisis Events and Managers' Concerns in Non-profit Organisations. Journal of Contingencies and Crisis Management, 11 (4), pp. 160-167.

23. Starbuck, W., Milliken, F. Challenger: Fine-Tuning the Odds Until Something Breaks.

24. Journal of Management Studies, 25 (4), pp.319-340.

25. Wilson, S. (2004) The Myths and Reality of Crisis Communication. October 15, (2), 2.

26. Wilson, B. G. (1992) Grisis Management: A Gase Study of Three American Universities'. Unpublished dissertation. University of Pittsburg, PA. 